\title{
EFL LEARNERS' SPEAKING ANXIETY AND ENGLISH SPEAKING ABILITY
}

\author{
Yeni Rina Handayani \\ Widya Mandala Catholic University Surabaya \\ yenirh.english@gmail.com \\ Agustinus Ngadiman \\ Widya Mandala Catholic University Surabaya \\ agustinusngadiman@gmail.com
}

\begin{abstract}
The aim of this study was to investigate the correlation between speaking anxiety and presentational English speaking ability. The subjects were the eleven graders of Senior High School in Surabaya. It consisted of 457 students whose age ranged between sixteen to seventeen years old. They came from social and science classes which were divided into seven science classes and five social classes. The result of the study revealed that there was a negative correlation between speaking anxiety and presentational English speaking ability. And there was also a negative correlation between speaking anxiety and each of speaking ability subskills.
\end{abstract}

Keywords: Speaking anxiety, speaking ability, presentational English speaking ability.

\section{INTRODUCTION}

English is an essential language in the world in global era since it is used in various situations in International relationship. There are ample interesting chances or opportunities to get a better job for someone who masters English. This reality increases the English speakers in the world. Based on the data of statistics portal in www.statista.Com, 1500 million people worldwide speak English, of whom 375 million are native speakers. Based on this data, in can be seen that a number of non- native speakers are bigger than the native speakers. Mastering English, especially speaking English is not a simple process. It is not only concerned with acquiring knowledge about grammar and pronunciation systems, it is a set of skills, something we learn to do, so the students need meaningful, interactive practice in the skill in order to learn to use the language (Gower, R., et al., 2005:85).Many people experience mental block against learning foreign language, although they are good learners in other situations (Horwitz, 1986:125). Learning a foreign language sometimes put the learner in uncomfortable situations because they have to learn a language which is completely different from their native language.

Nazir, et al. (2014: 1) found that among four language skills, speaking has always been a critical skill for ESL/ EFL learner. It is the most challenging of the 
four skills because it is a productive skill that involves a complex process of constructing meaning (Celce-Murcia \& Olshtain, 2000) cited by Ahmed (2014). Juhana (2012: 100) found there are some psychology factors such as fear of making mistakes, shyness, anxiety, and lack of motivation that hinder students from speaking in English class. Anxiety is one of factors influence reluctance problem among speakers. Almost all of EFL learners experience it in speaking.

Suleimenova (2013: 1) defined anxiety as distress or uneasiness of the mind caused by fear of danger or misfortune. In harmony, Cui (2011: 875) said that speaking anxiety is a kind of troubled feeling in the mind. Gaibani (2014:1) said that Anxiety is a state of uncomfortable emotion where danger is perceived, and the victim has a powerless feeling with the expression of tension in anticipation of danger. Performance anxiety involved communication apprehension, test anxiety, and afraid of negative evaluation (Horwitz, 1986: 127).Anxiety is a common problem in learning second or a foreign language. Speaking anxiety is a common problem faces by EFL learners. Almost all of EFL learners get anxious in speaking performance. Based on the previous studies, it found there is a relationship between speaking anxiety and speaking achievement, it triggers the writer to do a deeper research on speaking anxiety.

In the present study, the writer specifies the study on finding the correlation between speaking anxiety and presentational English speaking ability of EFL learners among high school students. Heaton (1990: 100) classified speaking ability into three sub-skills which covers speaking accuracy, speaking fluency, and speaking comprehensibility. Speaking accuracy consists the ability to speak in English grammatically, to use and to pronounce The English words correctly speaking fluency refers to the ability to speak in English fluently, while speaking comprehensibility refers to the ability to make the spoken easily to be comprehended by the listener. Based on the above classification, there are three minor-problems which are addressed in this research. (1) Is there a correlation between speaking anxiety and speaking accuracy of EFL learners? (2) Is there a correlation between speaking anxiety and speaking fluency of EFL learners? (3) Is there a correlation between speaking anxiety and speaking comprehensibility of EFL learners?

\section{MEHOD}

The population of the study was the eleven graders of Senior High School in Surabaya. It consisted of 457 students whose age ranged between sixteen to seventeen years old. They came from social and science classes which were divided into seven science classes and five social classes. Probability sampling with simple random selection was implemented to take the sample of the study. Mueller (1992:55) said that it was the way to randomly select a group of individuals for observation who represented the population of the study. The students in each class were divided into some groups. Each group consisted of 5 students. The writer chose one group from each class. The writer took 60 samples from the population randomly. It was an appropriate number of samples in quantitative study. Gay and Diehl cited by Yaghmaei (2015) indicated that in correlation research, at least 30 participants were required to establish a relationship. All groups had to be ready to present their topic because they were called randomly based on the lottery to present a topic in front of the classroom in 
a group. The topic of the presentation had been given a week before they presented it so the students had a week to prepare their presentation.

There were two kinds of quantitative data in this study. The first data were taken from the result of speaking anxiety questionnaire and presentational English speaking test. The writer administered Foreign Language Classroom Anxiety Scale (FLCAS) questionnaire designed by Horwitz (1986) to know degree of anxiety of the subjects. The higher FLCAS score indicated the higher degree of speaking anxiety and the lower FLCAS score indicated the lower degree of anxiety. The data of speaking anxiety questioner was ordinal data.

The second data were taken from the student's Presentational English speaking score that were taken during their presentation. Scoring rubric was used to measure the student's speaking presentation performance which is based on the sub-skills of speaking ability which covered accuracy, fluency, and comprehensibility. The types of the data that were taken from presentational English speaking test were ordinal data.

The speaking test that was used in the present study was extensive speaking in the form of group presentation. It was taken in the second half semester. The students were divided in groups. One group consisted of five students. The topic had been given a week before the students presented it. The teacher prepared the topics that were about tourist resort in some counties in the World. There were ten choices of countries including Indonesia, Malaysia, Japan, France, Singapore, Thailand, Filipina, Hong Kong, Australia, and Dubai. The writer chose those countries as choices because there were many interesting tourist resorts in those countries and most of the students familiar with those counties because most of them once having a holiday there. The students were given a chance to choose one of the ten choices. They should present the tourist resort in those countries in front of the classroom.

Speaking rubric was used to gain the students' presentational performance ability. The writer used speaking rubric which was designed by Heaton (1990: 100) which consisted of three sub-skills of speaking ability that were scored. The first was accuracy which covered pronunciation, grammatical, and lexical correctness. The second was fluency which covered the ability to speak smoothly without having to stop and pause a lot. The third was comprehensibility which covered the ability to deliver intention clearly or the intention could be understood by the listener easily. There were two raters during speaking test, the writer as a researcher and the collaborator who was one of English senior teachers in Petra 1 Senior High School. The writer chose her as a collaborator due to her experience in teaching English. Both raters were collaboratively scored the student's performance. The data that were gained by the raters from speaking test were ordinal data. It covered the data of the subject Presentational English speaking ability score and it consisted of the score of the three speaking sub-skills.

The speaking presentation test was scored based on student's performance. The researcher involved one of Senior English teachers who have been teaching in Petra 1 Senior High School for about fifteen years as a collaborator to score the student's performance, so there were two raters in speaking test. Both raters took the score during the subject presented their topic in front of the classroom. The subject speaking performances were scored by using speaking rubric adapted from Heaton (1990:100). It covered the overall the subject presentational English 
speaking performance score and the scoring of three sub-skills of speaking ability including accuracy, fluency, and comprehensibility. The raters used a range score from 1 to 6 for scoring each speaking sub-skills. The biggest number was for the best skills and vice versa the lowest number was for the worst skills. The scores that were gained by the raters were calculated to find the average score. The data that were gained from speaking test were ordinal data.

\section{RESULTS}

\section{Correlation between Speaking Anxiety and Speaking Accuracy}

In this study, the writer also analyzed the correlation between speaking anxiety and each of speaking ability sub-skills which covered speaking accuracy, fluency, and comprehensibility. To know degree of correlation between speaking anxiety and each of presentational English speaking ability sub-skills, the writer also used SPSS 16 in analyzing the data. The finding was presented in the following table.

Table 1: Correlation between Speaking Anxiety and Speaking Accuracy

\section{Correlations}

\begin{tabular}{|ll|l|l|}
\hline & $\begin{array}{l}\text { Speaking } \\
\text { Anxiety }\end{array}$ & $\begin{array}{l}\text { Speaking } \\
\text { Accuracy }\end{array}$ \\
\hline Speaking Anxiety & Pearson Correlation & 1 & $-.790^{* *}$ \\
& Sig. (2-tailed) & .000 \\
N & 60 & 60 \\
\hline Speaking Accuracy & Pearson Correlation & $-.790^{* *}$ & 1 \\
Sig. (2-tailed) & .000 & \\
N & 60 & 60 \\
\hline
\end{tabular}

**. Correlation is significant at the 0.01 level (2-tailed).

Based on the finding presented on table 1, Pearson correlation coefficient between speaking anxiety and speaking accuracy which was one of speaking ability sub-skills was -.790 and $\mathrm{p}<.01$. The negative Pearson correlation coefficient indicated there was negative correlation between speaking anxiety and speaking accuracy. The magnitude of the correlation was strong since it was in the range \pm .70 and 1.00 (Creswell, 2008), therefore the null hypothesis of the first minor problem was rejected and the alternative hypothesis was accepted. Correlation between Speaking Anxiety and Speaking Accuracy was drawn in scatter plot in the following figure. 
Figure 1: Correlation between Speaking Anxiety and Speaking Accuracy

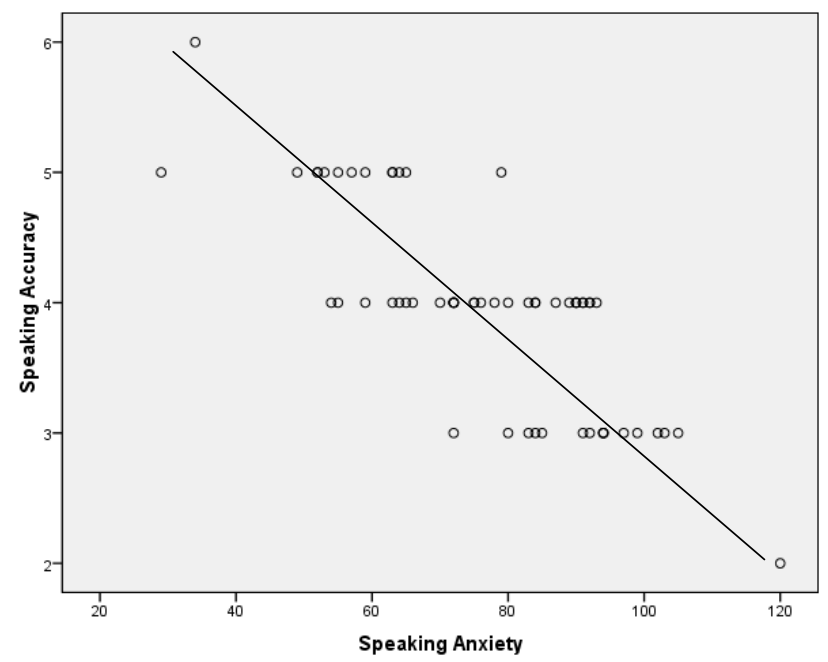

Based on figure 1, it could be described that the higher the subject's degree of anxiety, the lower their speaking accuracy score and the lower the subject's degree of anxiety, the higher their speaking accuracy score. Based on the above figure, it could be seen that the subject with high degree of anxiety spoke English with a low accuracy during presentation.

\section{Correlation between Speaking Anxiety and Speaking Fluency}

Correlation between speaking anxiety and speaking fluency which was the second speaking ability sub-skills was analyzed by the writer using SPSS 16 . The purpose was to know the degree of correlation between speaking anxiety and speaking fluency. The result of the analyzing could be seen in the following table.

Table 2: Correlation between Speaking Anxiety and Speaking Fluency

\section{Correlations}

\begin{tabular}{|ll|l|l|}
\hline & $\begin{array}{l}\text { Speaking } \\
\text { Anxiety }\end{array}$ & $\begin{array}{l}\text { Speaking } \\
\text { Fluency }\end{array}$ \\
\hline Speaking Anxiety & Pearson Correlation & 1 & $-.782^{* *}$ \\
Sig. (2-tailed) & & .000 \\
N & 60 & 60 \\
\hline Speaking Fluency & Pearson Correlation & $-.782^{* *}$ & 1 \\
Sig. (2-tailed) & .000 & \\
N & 60 & 60 \\
\hline
\end{tabular}

**. Correlation is significant at the 0.01 level (2-tailed).

Table 2 presented the correlation between speaking anxiety and speaking fluency. The Pearson correlation coefficient between speaking anxiety and speaking fluency was $-.782, \mathrm{p}<.01$. The negative value of correlation coefficient 
indicated that there was negative correlation between speaking anxiety and speaking fluency. The higher degree of speaking anxiety, the lower speaking fluency score. The magnitude of the correlation was strong since it was in the range \pm .70 and 1.00 (Creswell, 2008), therefore the null hypothesis of the second minor problem was rejected and the alternative hypothesis was accepted. Correlation between Speaking Anxiety and Speaking Fluency was drawn in Scatterplot in the following figure.

Figure 2: Correlation between Speaking Anxiety and Speaking Fluency

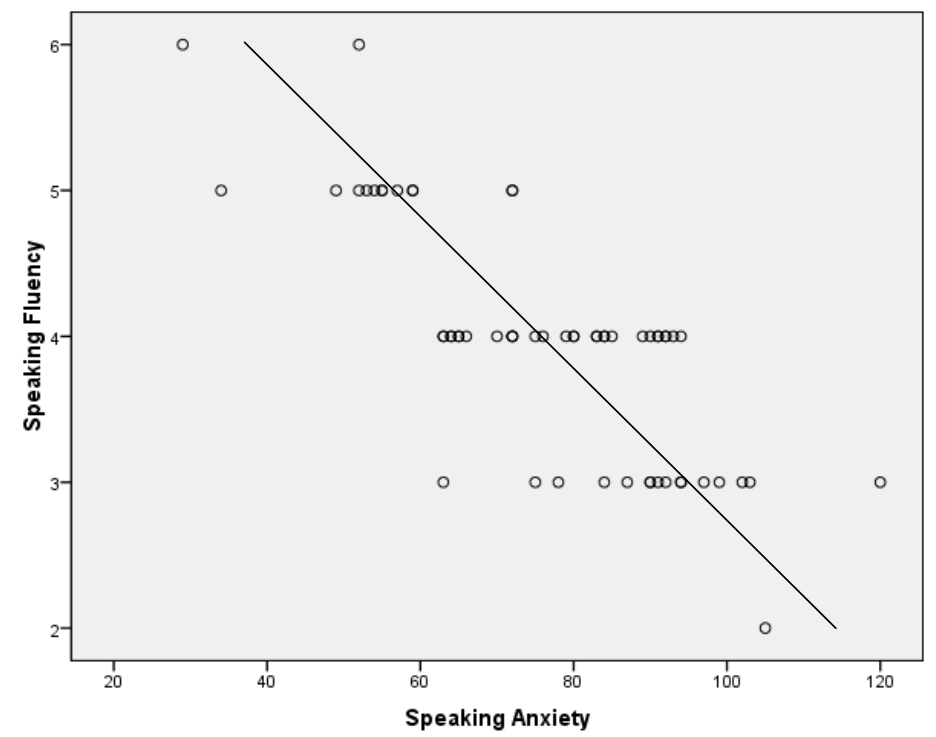

Based on figure 2 it could be described that the higher the subject's degree of anxiety, the lower their speaking fluency score and the lower the subject's degree of anxiety, the higher the subject's speaking fluency score. The subject who experienced a high degree of anxiety performed a low speaking fluency during presentational English speaking performance. On the other hand, the subject who experienced a low degree of anxiety got a better speaking fluency score because the subject could perform speaking fluently.

\section{Correlation between Speaking Anxiety and Speaking Comprehensibility}

Speaking comprehensibility was covered whether the spoken language used by the subject during presentation was comprehended by the listener or not. To know the correlation between speaking anxiety and speaking comprehensibility, the writer used Pearson Product Moment. The finding was described in the following table. 
Table 3: Correlation between Speaking Anxiety and Speaking Comprehensibility Correlations

\begin{tabular}{|ll|l|l|}
\hline & & $\begin{array}{l}\text { Speaking } \\
\text { Anxiety }\end{array}$ & $\begin{array}{l}\text { Speaking } \\
\text { Comprehensib } \\
\text { ility }\end{array}$ \\
\hline Speaking Anxiety & Pearson Correlation & 1 & $-.843^{* *}$ \\
& Sig. (2-tailed) & & .000 \\
& $\mathrm{~N}$ & 60 & 60 \\
\hline Speaking & Pearson Correlation & $-.843^{* *}$ & 1 \\
Comprehensibility & Sig. (2-tailed) & .000 & \\
& $\mathrm{~N}$ & 60 & 60 \\
\hline
\end{tabular}

**. Correlation is significant at the 0.01 level (2-tailed).

Table 3 presented the correlation between speaking anxiety and speaking comprehensibility. Based on the data presented in table 3, the Pearson correlation coefficient was $-.843, \mathrm{p}<.0$. the negative value of Pearson coefficient correlation indicated that the direction of correlation between speaking anxiety and speaking comprehensibility was negative. The magnitude of the correlation was strong since it was in the range \pm .70 and 1.00 (Creswell, 2008), therefore the null hypothesis of the third minor problem was rejected and the alternative hypothesis was accepted. The correlation between speaking anxiety and speaking comprehensibility was described in scatter plot in the following figure.

Figure 3: Correlation between Speaking Anxiety and Speaking Comprehensibility

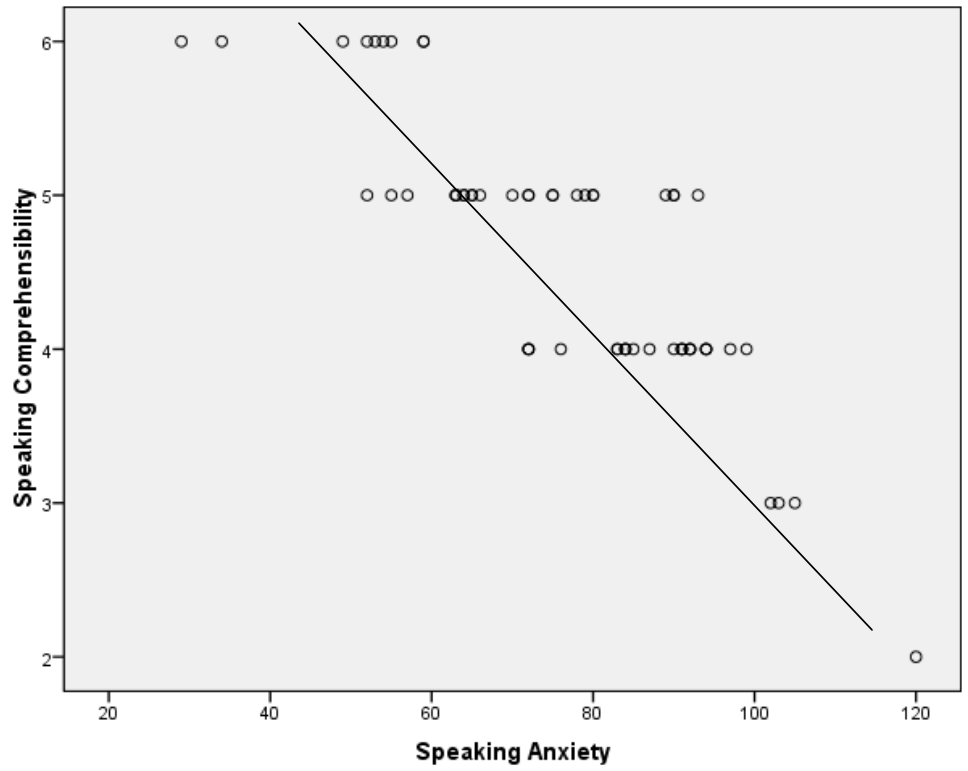

Based on figure 3, it could be described that the higher the subject degree of anxiety, the lower their speaking comprehensibility score and the lower the subject's degree of anxiety, the higher their speaking comprehensibility scores. The subject who experienced a high degree of anxiety shown their spoken during 
presentation was difficult to be understood by the listener. It made the subject got a low speaking comprehensibility score.

\section{DISCUSSION}

Concerning to the correlation between speaking anxiety and presentational English speaking ability, the finding of this study described that there was negative correlation between speaking anxiety and Presentational English speaking ability. It described that the higher the degree of the student's speaking anxiety score, the lower their presentational English speaking performance score. Pearson coefficient correlation between speaking anxiety and Presentational English speaking performance $(\mathrm{r}=-0.914, \mathrm{p}<0.01)$. The direction of the correlation between speaking anxiety and presentational English speaking performance was negative. it was in harmony with the finding of some previous studies (Philips, 1992; Kamridah, 2015; Azizifar, et al, 2014; Awan, et al, 2010) which found the same result. The subject who experienced a high degree of speaking anxiety showed a poor oral speaking achievement. It is against the result of Lian, et al (2014) study which found that there was positive correlation between English language anxiety and oral English test achievement which meant the higher the degree of speaking anxiety, the higher the oral English achievement.

Concerning to the correlation between speaking anxiety and speaking accuracy, this study found that there was a negative correlation between speaking anxiety and speaking accuracy. The finding described that Pearson Correlation coefficient between speaking anxiety and speaking accuracy was -.790, p<.01. The negative value indicated the direction of the correlation between the two variables was negative. The higher the subject degree of anxiety, the lower the subject's speaking accuracy score. Gower, et al (2005: 99) underlined that accuracy was important part of speaking skills. It covered the correct use of vocabulary, grammar, and pronunciation. This study found that the students who experienced a high degree of speaking anxiety got a low speaking accuracy score because the subject made serious pronunciation errors as well as many basic grammatical and lexical errors and showing no evidence of having mastered any of the language skills and areas practiced in the course (Heaton, 1990: 100)

Concerning to the correlation between speaking anxiety and speaking fluency, this study found there was negative correlation between speaking anxiety and speaking fluency. The finding described the Pearson Correlation coefficient between speaking anxiety and speaking fluency was $-.782, \mathrm{p}<.01$. The negative value indicated that the direction of correlation between speaking anxiety and speaking fluency was negative. The more anxious the subject, the worse their speaking fluency score. The subject who experienced a high degree of speaking anxiety performed a poor speaking fluency. Gower, et al (2005: 100) underlined that fluency was related to the ability to keep going when speaking spontaneously. The students who experienced a high degree of speaking anxiety lack of this ability. It against the finding of a study by Salem, et al (2004: 170) which found there was no correlation between speaking anxiety and oral fluency performance among female students.

Concerning to the correlation between speaking anxiety and speaking comprehensibility, this study found there was negative correlation between speaking anxiety and speaking comprehensibility. Pearson correlation coefficient 
between speaking anxiety and speaking comprehensibility was $-.843, \mathrm{p}<.01$. The negative value indicated the negative correlation between speaking anxiety and speaking comprehensibility. It meant that the more anxious the subject, the worse their speaking comprehensibility score. Speaking comprehensibility was related to the easiness to comprehend a spoken delivered by the subject. It was hardly anything of what the subject who experienced high degree of anxiety said could be understood. Heaton (1990:100) underlined that comprehensibility score was based whether or not the subject's spoken could be understood by the listener. The range score was based on the degree of the easiness the spoken could be understood by the listener.

\section{CONCLUSION}

Speaking anxiety is discovered to have strong negative correlation with presentational English speaking score $(r=-0.914, p<.01)$. The higher the subject's degree of anxiety, the lower their Presentational English speaking performance score and the lower the subject degree of anxiety, the higher their presentational English speaking performance score that they achieved.

Furthermore, the correlation between speaking anxiety and speaking accuracy is strong negative correlated $(\mathrm{r}=-790, \mathrm{p}<.01)$. The negative value indicated that the correlation between speaking anxiety and speaking accuracy is negative. It means that the higher the subject degree of anxiety, the lower their speaking accuracy score and vice versa the lower the degree of the subject's speaking anxiety, the higher their speaking fluency score. In other word the subject with high degree of anxiety have a low ability in speaking accurately.

This study also found there is strong negative correlation between speaking anxiety and speaking fluency $(\mathrm{r}=-782, \mathrm{p}<.01)$. It indicates that the higher degree of the subject's speaking anxiety, the lower their speaking fluency score and the lower the degree of the subject speaking anxiety, the higher their speaking fluency score. The subject with high degree of anxiety is lack of the ability to keep the conversation going. While the subject with low degree of speaking anxiety has a good ability to keep the conversation going.

Concerning to the correlation between speaking anxiety and speaking comprehensibility, his study found there is strong negative correlation between speaking anxiety and speaking comprehensibility $(r=-0.843, p<.01)$. It indicates that the higher degree of the subject's speaking anxiety, the lower their speaking comprehensibility score and the lower degree of the subject's speaking anxiety, the higher their speaking comprehensibility score. The high of speaking comprehensibility score indicates that the spoken of the subject during presentation is easy to comprehend by the listener and vice versa the lower the speaking comprehensibility score indicated that the spoken of the subject during presentation was hard to comprehend.

In short it can be concluded that there was strong correlation between speaking anxiety and presentational English speaking performance. There is also a strong correlation between speaking anxiety and each of English speaking ability sub-skills. 


\section{SUGGESTION}

Based on the result of this study, it finds that there is a strong negative correlation between speaking anxiety and presentational English speaking score among EFL learners in the eleventh grade of senior high school. It means that the more anxious the subject, the worse their presentational English speaking score. This study also finds there is a strong negative correlation between speaking anxiety and each of speaking ability sub-skills (speaking accuracy, speaking fluency, speaking comprehensibility). The higher the degree of the subject's speaking anxiety, the lower each of their speaking ability sub-skills' score. Further study is necessarily recommended to discover the effect of speaking anxiety on presentational English speaking ability, speaking accuracy, speaking fluency, and speaking comprehensibility.

Furthermore, having observed the correlation between speaking anxiety and presentational English speaking performance, speaking anxiety and each of speaking ability sub-skills, the writer suspects that the tense situation in the classroom during presentation make the subject anxious. For the English teacher, the writer suggests to create more enjoyable situation in speaking class to reduce the subject speaking anxiety.

\section{REFERENCES}

Ahmed, Sawsan and Alamin, A. (2014). Assessing Speaking Ability in Academic Context for Fourth Year Taif University Students. International Journal of English Linguistics 4(6), 97-103

Awan. R, et.al. (2010). An Investigation of Foreign Language Classroom Anxiety and Its Relationship With Students' Achievement. Journal of College Teaching and Learning, 7(11), 33-40.

Azizifar, et.al. (2014). The effect of Anxiety on Iranian EFL Learners Speaking Skill. International Research Journal f Applied and Basic Sciences, 8(10), 1747-1754.

Astan, Cinthia (2014). The Correlation Between Vocabulary Size and The Three Levels of Reading Comprehension. Widya Mandala Catholic University Thesis. Surabaya

Cui, Jingjing. (2011). Research on High School Students' English Learning Anxiety. Journal of Language Teaching and Research, 2(4), 875-880.

Gaibani \& Elmenfi. (2014). The Role of Gender in Influencing Public Speaking Anxiety. International Journal of English Linguistics, 2(2), 105-116.

Gower, R.,et.al. (2005). Teaching Practice: A Handbook for Teachers in Training. Between Town Road, Oxford: A Division of Macmillan Publishers Limited.

Horwitz, Elain K, et.al. (1986). Foreign Language Classroom Anxiety. The Modern Language Journal, 70(2), 125-132.

Heaton, J. B. (1990). Writing English Language Tests. New York: Longman inc.

Juhana. (2012). Psychological Factors that Hinder Students from Speaking in English Class (a Case Study in a Senior High School in South Tangerang, Banten, Indonesia). Journal of Education and Practice, 3(12), 100-110. 
Journal of English Teaching Adi Buana, Vol. 03 No. 01, April 2018

Kamridah. (2015). Correlation Between Level of Anxiety and Public Speaking Performance through Systematic Learning Approach in Learning Language . International Journal of Science and Research. ISSN (Online): 2319-7064

McMillan,James H. (2008). Educational Research. United States of America: Pearson Education Inc.

Mueller, Delbert. (1992). An Interactive Guide to Educational Research. United States of America: Allyn and Bacon a Devision of Simon \& Schuster Inc.

Phillips, Elaine M. (1992). The Effects of Language Anxiety on Students' Oral Test Performance and Attitudes. The Modern Language Journal, 76(2), 14-26.

Suleimenova, Z. (2013). Speaking Anxiety in a Foreign Language Classroom in Kazakhstan . Procedia Sociaal and Behavioral Sciences, 1860-1868. 